are either destroyed in the pulmonary artery or remain latent within the vessel wall without parenchymal invasion. Tumor pulmonary embolism therefore does not necessarily imply metastatic disease., ${ }^{4,5}$

In this patient the embolic material on the right side was resolved, but not on the left, probably because of total occlusion. The operation restored the circulation to normal, but an embolectomy did not suffice - a true endarterectomy was required because of the fibrotic, chronic nature of the lesion, with distal thrombosis. Operation in this patient resulted in the complete resolution of symptoms and was likely curative. To our knowledge, this is the first known case of removal of renal cell carcinoma embolus by pulmonary thromboendarterectomy.

\section{REFERENCES}

1. Jamieson SW, Auger WR, Fedullo PF, et al. Experience and results with 150 pulmonary thromboendarterectomy opera- tions over a 29 -month period. J Thorac Cardiovasc Surg 1993;106:116-25.

2. Samsonov VA. Thromboembolism and tumor embolism of the pulmonary artery as a cause of death in oncourologic diseases. Arfhiv Patol 1983,45:73-6.

3. Henriksson C, Aldenborg F, Lindberg S, Pettersson S. Pulmonary embolism in renal cell carcinoma with vena cava extension. Scand J Urol Nephrol 1988;22:215-8.

4. Isringhaus $H$, Naber M, Kopper B. Successful treatment of tumor embolism of a hypernephroma with complete occlusion of the left pulmonary artery. Thorac Cardiovasc Surg 1987;35: 65-6.

5. Daughtry JD, Stewart BH, Golding LAR, Groves LK. Pulmonary embolus presenting as the initial manifestation of renal cell carcinoma. Ann Thorac Surg 1977;24:178-81.

\title{
RIGHT HEART BYPASS WITH AN EXTRACARDIAC CONDUIT FOR FUNCTIONALLY SINGLE VENTRICLE WITH ANOMALOUS PULMONARY VENOUS CONNECTION TO THE RIGHT ATRIUM
}

\author{
Charles S. Roberts, MD, Paul Peters, FRCS, and Christopher Lincoln, FRCS, London, United Kingdom
}

Several methods for bypassing the right side of the heart have been reported in the past 40 years. Our usual technique is total cavopulmonary connection as described by de Leval and associates ${ }^{1}$ in 1988 . Herin we present the case history of a child with a functionally single ventricle and totally anomalous pulmonary venous drainage to the right atrium, which necessitated an unusual technique.

Clinical summary. A 2-year-old child was referred to the Royal Brompton Hospital with cyanotic complex congenital heart disease. She had been cyanotic from birth, had become increasingly breathless, and had recurrent chest infections. She had clubbing of the fingers and toes and a loud precordial systolic murmur. Echocardiography and cardiac catheterization revealed bilateral superior venae cavae (SVCs) and a single right-sided inferior vena cava (IVC), isomerism of the right atrial appendages with a large atrial septal defect, a univentricular atrioventricular connection via a common atrioventricular valve to

From the Royal Brompton Hospital, Sydney Street, London, United Kingdom.

Received for publication Jan. 22, 1997; accepted for publication Feb. 10, 1997.

Address for reprints: Christopher Lincoln, FRCS, Royal Brompton Hospital, Sydney Street, London SW3 6NP, United Kingdom.

J Thorac Cardiovasc Surg 1997;114:297-8

Copyright (C) 1997 by Mosby-Year Book, Inc.

0022-5223/97 $\$ 5.00+0 \quad \mathbf{1 2 / 5 4 / 8 1 1 2 2}$ a dominant right ventricle, a hypoplastic left ventricle, double-outlet right ventricle with pulmonary stenosis, and totally anomalous pulmonary venous connection to the right atrium, near the orifice of the SVC. She did not have subaortic stenosis, and the mean pulmonary arterial pressure was $11 \mathrm{~mm} \mathrm{Hg}$.

A conventional total cavopulmonary connection was attempted. Bilateral bidirectional Glenn shunts were constructed. A lateral intraatrial baffle was placed to direct IVC blood to the pulmonary arteries, attempting to avoid the pulmonary venous connection in the right atrium. Nevertheless, when cardiopulmonary bypass was being discontinued, it became evident that pulmonary venous return was obstructed. The baffle was therefore taken down. Postoperatively, right upper lobe consolidation occurred because of apparent obstruction of the pulmonary vein to the lobe. Otherwise, recovery was uneventful and the child was discharged with an arterial oxygen saturation of $80 \%$.

At the age 3 years 10 months, the child underwent a second echocardiogram and cardiac catheterization. The bilateral bidirectional Glenn shunts were patent, mean pulmonary arterial pressure was $9 \mathrm{~mm} \mathrm{Hg}$, and ventricular function was good. Arterial oxygen saturation was $86 \%$. A second operation was undertaken. With the use of a predominantly extracardiac conduit (19 mm polytetrafluoroethylene tube graft), IVC blood was directed to the pulmonary arteries (Fig. 1). The proximal end of the tube graft was sewn to the IVC orifice in the right atrium. A fenestration $4 \mathrm{~mm}$ in diameter was made in the tube graft 


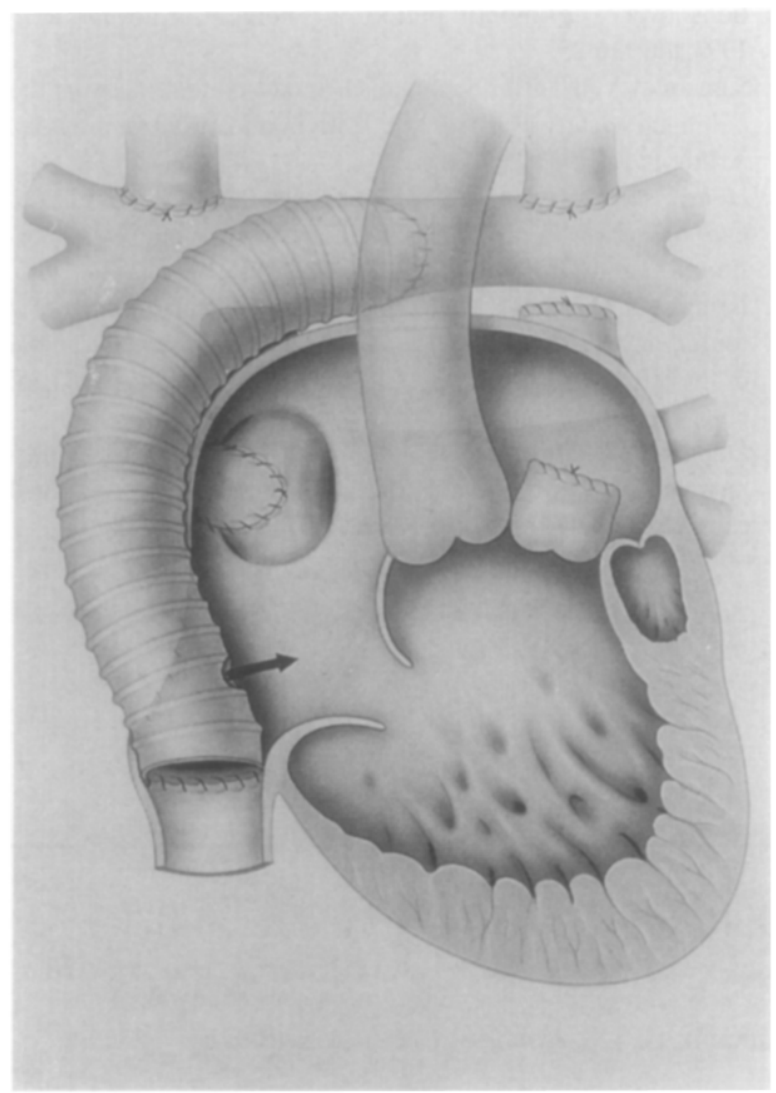

Fig. 1. Total cavopulmonary connection using a predominantly extracardiac conduit in a child with a functionally single ventricle and anomalous pulmonary venous connection to the right atrium. A $4 \mathrm{~mm}$ fenestration was made in the intraatrial portion of the conduit.

within the right atrium. The tube graft was then brought out through the right lateral wall of the right atrium and its distal end was sewn to the central portion of the right pulmonary artery (medial to the right bidirectional Glenn anastomosis). By creating a primarily extracardiac pathway for IVC flow to the pulmonary arteries, we avoided the anomalous pulmonary venous connection in the upper right atrium. A patch was used to enlarge the right posterolateral aspect of the confluence of the pulmonary veins.

Postoperative recovery was uneventful except for development of bilateral pleural effusions, which necessitated drainage. Echocardiography showed no obstruction to systemic or pulmonary venous pathways and good ventricular function. Arterial oxygen saturations were above $90 \%$ and the child was discharged to her home after 21 hospital days.

Discussion. Total cavopulmonary connection was our operative goal in this child with a functionally single ventricle. Our usual technique was not possible, however, because of the pulmonary venous connection to the right atrium near the orifice of the SVC. The predominantly extracardiac conduit avoided the potential obstruction of pulmonary venous return.

In 1990 Marcelletti and associates ${ }^{2}$ described four patients who were treated by placing an extracardiac conduit from the IVC to the pulmonary arteries. ${ }^{2}$ One had similar but not identical anatomy to our patient. A further 28 cases were reported in 1992, none of which involved anomalous pulmonary venous connection to the right atrium. ${ }^{3}$ The technique of creating a fenestration in the tube graft in its intraatrial portion was recommended to us by de Leval in a personal communcation. A different technique of fenestration has been described by Black and associates, ${ }^{4}$ who interposed a small tube graft between the extracardiac conduit and the right atrium.

\section{REFERENCES}

1. de Leval MR, Kilner P, Gewillig M, Bull C. Total cavopulmonary connection: a logical alternative to atriopulmonary connection for complex Fontan operations-experimental studies and early clinical experience. J Thorac Cardiovasc Surg 1988; 96:682-95.

2. Marcelletti C, Corno A, Giannico S, Marino B. Inferior vena cava-pulmonary artery extracardiac conduit: a new form of right heart bypass: J Thorac Cardiovasc Surg 1990;100:228-32.

3. Giannico S, Corno A, Marino B, Cicini MP, Gagliardi MG, Amodeo A, et al. Total extracardiac right heart bypass. Circulation 1992;86(Suppl):II110-7.

4. Black MD, van Son JAM, Haas GS. Extracardiac Fontan operation with adjustable communication. Ann Thorac Surg 1995;60:716-8. 